\title{
GÓMEZ BERNAL, VANESSA (2013). Dis-capacidad y género: Una mirada feminista sobre la construcción social de categorías invalidantes. Jaén: Diputación de Jaén, 163 pp.
}

\section{Beltrán Roca Martínez \\ Universidad de Cádiz}

Hay monografías que se escriben desde la neutralidad y la distancia, y hay monografías que parten de la implicación y las vivencias del autor. Los mejores trabajos antropológicos suelen ser del segundo tipo, pues rehuyen de la frialdad académica para adentrar a los lectores en la profundidad de las subjetividades-emociones, convicciones, miedos, anhelos, etc.-de los actores sociales. Este es el caso de Dis-capacidad y género: Una mirada feminista sobre la construcción social de categorías invalidantes. La autora, Vanesa Gómez Bernal, combina la implicación militante, la crítica feminista y el rigor científico para explorar la construcción social de la discapacidad. Para ello, se adentra en las narraciones y experiencias de mujeres discapacitadas, identificando los condicionamientos estructurales, el universo de relaciones de poder, en el que desarrollan sus vidas.

Este libro es una versión adaptada del trabajo de Suficiencia Investigadora de Vanesa Gómez Bernal, que ha sido galardonado con el VIII Premio de Investigación en Políticas de Igualdad "Carmen de Michelena” de la Diputación Provincial de Jaén. Una primera cuestión a destacar del libro es la exitosa conversión de un informe con finalidad académica en un libro destinado a una audiencia más amplia sin perder la profundidad y rigurosidad científica. La autora se encuentra en la actualidad finalizando su tesis doctoral en la Universidad de Cádiz sobre la misma problemática. Es de esperar que sus futuras publicaciones nos permitan conocer con mayor detalle y a partir de una 
muestra más amplia estos procesos de construcción de la discapacidad y los mecanismos de poder que se ejercen sobre las mujeres etiquetadas como discapacitadas.

Discapacidad y género está estructurado en cinco capítulos. El primer capítulo, "Un conocimiento situado: ¿Cómo ver? ¿Desde dónde ver? ¿Para qué mirar?”, explicita la posición desde la que la autora reflexiona sobre su objeto de estudio. Por un lado, se ubica en el ámbito de la crítica feminista que cuestiona los fundamentos epistemológicos androcéntricos de la ciencia tradicional y revaloriza la experiencia de os sujetos como un "acto total", que implica cuerpo, mente, razón y emoción como un todo (Gregorio Gil, 2006). Por otro lado, la autora revela la importancia de su experiencia vital como persona catalogada como mujer con discapacidad en su aproximación, que pretende realizar a través del "extrañamiento antropológico".

Una primera advertencia de la investigadora se refiere al concepto de discapacidad. El uso de categorías no es sino una expresión de poder, y tiene el efecto de reforzar las relaciones de dominación sobre los grupos y las personas categorizadas. Etiquetas como inválido, minusválido o incapacitado abundan en los documentos periodísticos, médicos y administrativos, operando como vehículos de justificación y legitimación de la dominación. De este modo, el discurso de la discapacidad forma parte de una tecnología político-ideológica que configura relaciones de poder, desigualdad social. Por ello, desde ámbitos militantes se aboga por otros conceptos como diversidad funcional, díscolacapacidad, mujer no estándar o alter-valía. La autora subraya: "La discapacidad no es una característica objetiva aplicable a la persona, sino una construcción interpretativa y discursiva inscrita en una cultura en la que en virtud de su particular modo de definir lo normal, la discapacidad sería una desviación de dicha norma” (p. 21).

El capítulo segundo, titulado "Desenmascarando el estado de la cuestión desde una fundamentación interpretativa”, es el más extenso, probablemente demasiado en relación al capítulo descriptivo-analítico. En él la autora engloba diferentes cuestiones: el marco teórico por un lado, y el contexto jurídico, administrativo y asociativo del problema de investigación. En la primera parte defiende el uso del concepto de campo de Bourdieu en el caso de la discapacidad. Al fin y al cabo este espacio contiene relaciones sociales, lógicas, actores y disposiciones diferenciados de otros espacios sociales. Una característica de este campo es que hasta hace poco ha prevalecido un enfoque individual, médico o patológico, que se centraba más en el sujeto que en las dimensiones socio-culturales y políticas. Con el tiempo se ha pasado a un "modelo social de la discapacidad", que enfatiza dichos factores (López González, 2007). Posteriormente se ofrece una genealogía de los distintos modelos explicativos de la discapacidad: desde el modelo presidencialista de índole religioso, hasta el enfoque de las capacidades de Amartya Sen, pasando por el modelo social-que enfatiza las causas sociales de la discapacidad-el modelo médicorehabilitador o el modelo de la diversidad. 
Tras un exhaustivo recorrido por las teorías feministas y de a identidad, el capítulo continúa desgranando el papel del Estado en la construcción de la discapacidad. Por ejemplo, analiza cómo la Clasificación Internacional del Funcionamiento, la Discapacidad y la Salud de la OMS, de 2001, opera como un dispositivo de saber que s convierte en herramienta de poder que ordena y gradúa las discapacidades en función de su mayor o menor proximidad a un determinado estado de salud considerado "óptimo" (p. 77). En la misma dirección funciona el Real decreto 1856/2009, de 4 de diciembre, en el Estado español. Uno de los aspectos más destacados de este complejo jurídicopolítico de la discapacidad es el no reconocimiento del cruce de factores de género y discapacidad, que produce discriminaciones complejas y estructurales (p.87). El capítulo termina ofreciendo un mapeo y un análisis los discursos y prácticas del tejido asociativo, como el Movimiento de Vida Independiente, el real patronato sobre Discapacidad, el Comité Español de Representantes de Personas con Discapacidad o la Confederación Coordinadora Estatal de Minusválidos Físicos y Orgánicos de España.

El tercer capítulo, "Proceso de investigación", incluye la hipótesis, objetivos y metodología del trabajo. La autora se propone "comprender la construcción de la identidad a través de os parámetros de género y discapacidad" (p. 102). Para ello sigue una metodología cualitativa, que permite capturar los significados de los actores sociales en sus propios términos. Utiliza las técnicas de la observación participante y la entrevista semiestructurada individual y grupal, así como la observación de fuentes documentales. Pese a lo acertado de su estrategia investigadora, en este apartado he echado en falta una justificación del ámbito geográfico seleccionado, una descripción de los escenarios de la observación y una caracterización más detallada de las personas entrevistadas.

El cuarto capítulo, titulado "Informe de investigación", es a mi juicio el más conmovedor e interesante. A través de los testimonios orales de los informantes, la investigadora analiza la construcción identitaria, el papel de la administración, las experiencias cotidianas y los determinantes estructurales de las personas catalogadas como discapacitadas. Termina apuntando las diferentes experiencias y desigualdades entre hombres y mujeres con discapacidad. El quinto y último capítulo, "Conclusiones", recapitula el análisis realizado enfatizando el papel de las categorías de discapacidad y género como dispositivos de poder, que operan a través de procesos de estigmatización.

La monografía Dis-capacidad y género presenta, a mi modo de ver, algunas cuestiones mejorables. En primer lugar, considero que el apartado descriptivo-analítico está descompensado en relación al extenso marco teórico. En segundo lugar, pienso que la forma de presentar los testimonios, intercalando extractos de entrevistas con análisis de la autora debe ser complementado con el uso de una selección de relatos de vida más completos que permitan al lector empalizar, adentrarse en las experiencias vitales de los sujetos estudiados para amplificar la visión holística. En tercer lugar, encuentro la muestra 
de entrevistados algo reducida (aunque para un trabajo de Suficiencia Investigadora es, valga la redundancia, más que suficiente). A pesar de estos pequeños inconvenientes, Dis-capacidad y género, contiene determinados aspectos positivos que lo convierten en un libro fundamental. En primer lugar, el sólido marco teórico expuesto, que refleja un excelente manejo de las teorías sociológicas, antropológicas, feministas y la bibliografía específica sobre discapacidad. En segundo lugar, la riqueza de los testimonios orales de los actores, que nos permiten conocer cómo las normas y procedimientos burocráticos y el sistema médico-científico configuran relaciones estructurales de poder. En tercer lugar, destaca la claridad expositiva y la excelente capacidad de redacción de Vanesa Gómez Bernal. Por todo ello, Dis-capacidad y género es un libro de referencia para los estudios sobre discapacidad, aunque también contiene claves importantes para entender determinados aspectos de la teoría sociológica y del feminismo. Cuando la autora concluya la tesis doctoral, no me cabe duda de que nos sorprenderá con importantes avances, ampliaciones y profundizaciones.

\section{Referencias bibliográficas}

Gregorio Gil, Carmen (2006). "Contribuciones feministas a problemas epistemológicos de la disciplina antropológica: representación y relaciones de poder". AIBR, Revista de Antropología Iberoamericana, $\mathrm{n}^{\circ}$, pp. 22-39.

López González, María (2007). "Discapacidad y género. Estudio etnográfico sobre mujeres discapacitadas". Educación y diversidad, nº1, pp.137-171. 